\title{
Functional Neuroimaging in Rodents Using Cerebral Blood Flow SPECT
}

\author{
Anja M. Oelschlegel ${ }^{1,2 \dagger}$ and Jürgen Goldschmidt ${ }^{1 *}$ \\ ${ }^{1}$ Department of Systems Physiology of Learning, Leibniz Institute for Neurobiology, Magdeburg, Germany, ${ }^{2}$ Institute of \\ Anatomy, Medical Faculty, Otto-von-Guericke University, Magdeburg, Germany
}

\section{OPEN ACCESS}

Edited by: Adriana Tavares, University of Edinburgh, United Kingdom

Reviewed by: Wang $X$,

Zhejiang University, China Paul Vaska Stony Brook University, United States

*Correspondence: Jürgen Goldschmidt juergen.goldschmidt@

lin-magdeburg.de

${ }^{\dagger}$ Present address:

Anja M. Oelschlegel, Research Group Neuroplasticity, Leibniz Institute for Neurobiology, Magdeburg, Germany

Specialty section

This article was submitted to Medical Physics and Imaging, a section of the journal Frontiers in Physics

Received: 15 December 2019

Accepted: 15 April 2020

Published: 12 June 2020

Citation: Oelschlegel AM and Goldschmidt J (2020) Functional Neuroimaging in Rodents Using Cerebral Blood Flow

SPECT. Front. Phys. 8:152.

doi: 10.3389/fphy.2020.00152
The brain-wide activation patterns that underlie, generate, and change the behavioral outputs in rodents, the main animal models in biomedical research, are difficult to assess in vivo. The standard tool for whole-brain imaging of spatiotemporal activation patterns in rodents is BOLD fMRI, but the technique requires the animals to be immobilized inside the scanners. One of the few methods that can provide in vivo images of brain-wide patterns of neural activity from unrestrained animals outside scanner environments is single-photon emission computed tomography (SPECT) imaging of cerebral blood flow (CBF). During ongoing behavior, animals are intravenously injected with ${ }^{99 m} \mathrm{Tc}-\mathrm{HMPAO}$ (99m-technetium hexamethylene propyleneamine oxime), a lipophilic tracer that, after accumulation in the brain in a flow-dependent manner, is rapidly converted to a hydrophilic compound that remains trapped in the brain and shows no redistribution. The ${ }^{99 \mathrm{~m}} \mathrm{Tc}$ brain distribution, reflecting the average blood flow during the time of injection, can be read out in the anesthetized animal after injection. Similar in rationale to ${ }^{18} \mathrm{~F}$-2-fluoro-2-deoxy-glucose $\left({ }^{18} \mathrm{~F}\right.$-FDG) positron emission tomography (PET), ${ }^{99 m}$ TC-HMPAO SPECT provides static images of spatial patterns of neural activity from awake behaving rodents, but the spatial resolution can be higher and the stimulation times substantially shorter. In this review, we present an overview about the underlying rationales and principles of functional CBF SPECT imaging in rodents, give a short summary of the experimental procedures, and discuss the advantages, drawbacks, and perspectives of the technique within the framework of methods for imaging brain-wide activation patterns in awake behaving rodents.

Keywords: functional neuroimaging, small-animal SPECT, cerebral blood flow, PET, fMRI

\section{INTRODUCTION}

Rodents, in particular rats and mice, serve as the main model organisms for studying the structure and function of the mammalian brain in basic and applied neurosciences. With brain sizes in the cubic centimeter range-about $0.5 \mathrm{~cm}^{3}$ in mice and $2 \mathrm{~cm}^{3}$ in rats-these rodents pose particular challenges for neuroimaging techniques, especially techniques for in vivo imaging of the entire organ.

Rodent brains are several orders of magnitude larger than the brains of small vertebrates such as the zebrafish or common invertebrate model organisms such as the fruit fly Drosophila and the roundworm Caenorhabditis elegans. In addition, myelinated fiber bundles traverse the adult rodent brains, strongly increasing the scattering of electromagnetic waves in the visible range. In contrast to the transparent brains of zebrafish larvae or C. elegans, which can be optically imaged as a whole 
at cellular resolution in vivo [1,2], optical in vivo imaging of entire rodent brains at this resolution is not possible.

With respect to penetration depths and fields of view, rodent brains can easily be imaged with X-ray CT, MRI, PET, or SPECT, medical imaging techniques developed for human imaging. However, with brain volumes about a thousand times smaller than the human brain, substantial increases in spatial resolution are required if rodent brains should be imaged with at least the same relative resolution-relative to the brain size-as in humans.

Techniques for imaging the entire brain are of particular relevance in neuroscience. Brains are characterized by high degrees of global and local anatomical and functional interconnectivities between single neurons and neuronal ensembles. This network topology implies that, as a general rule, changes in behavioral output are mediated by activation changes in distributed neuron populations. In fact, even apparently simple behaviors, e.g., fear behavior [3], have been shown to be governed by complex brain-wide network activations. Explaining the changes in behavior that genetic alterations or manipulations, protein modifications, pharmacological treatments, and artificial or natural stimulations of cell ensembles might cause requires identification of the network activation patterns.

An ideal method for functional neuroimaging would be able to image in vivo brain-wide patterns of neural activity with high spatial (single-cell) and temporal (millisecond) resolution in behaving unrestrained animals. High-throughput imaging, repeated imaging over long time spans, and little to no interferences with experimental set-ups would be additional benefits.

Optical methods in invertebrates and the zebrafish larva as a small vertebrate come close to these demands $[1,2]$. For the mouse brain, however, no such methods are available, and it remains dubious whether techniques for single-cell-resolution in vivo imaging of the activation patterns of the $\sim 70$ million neurons in the mouse brain [4] can be developed at all. All currently available methods operate at substantially lower resolutions and suffer from more or less severe drawbacks.

The prevailing approach to assessing the brain-wide network behavior in the rodent brain is functional magnetic resonance imaging based on blood-oxygenation-level-dependent contrast (BOLD fMRI). Spatial and temporal resolutions rank among the highest in rodent whole-brain imaging, but animals have to be restrained inside scanners. In vivo images of brain-wide activation patterns in unrestrained, behaving rodents can be obtained using tracer techniques. Rodents are injected before or during the behavior of interest with tracers that accumulate in the brain in an activity-dependent manner. Tracers that show no relevant redistribution can be imaged in anesthetized animals after the experiment. Three tracers with three different imaging modalities are commonly used, the glucose analog ${ }^{18} \mathrm{~F}$-2-fluoro2 -deoxy-glucose $\left({ }^{18} \mathrm{~F}-\mathrm{FDG}\right)$ for positron emission tomography (PET) imaging, the calcium analog manganese for manganeseenhanced MRI (MEMRI), and the blood flow tracer ${ }^{99 \mathrm{~m}} \mathrm{Tc}-$ HMPAO for SPECT imaging. As one of the main drawbacks, these methods can provide only a static view of the average activity during the uptake period. What makes these approaches attractive is that there are few constraints on the behavioral set-ups to be used and the simplicity of the methods with respect to the treatments of the animals.

We here review one of the approaches, functional neuroimaging using CBF SPECT. We first describe the historical development and the rationales of using tracers for imaging cerebral blood flow and give an overview of the principles of SPECT imaging in small animals. We then explain the experimental procedure and discuss the approach in the framework of the diverse techniques for brain-wide functional neuroimaging in rodents.

\section{IMAGING REGIONAL CEREBRAL BLOOD FLOW USING TRACER TECHNIQUES}

Functional neuroimaging has its roots in studies of cerebral blood flow in mammals. In 1948, Kety and Schmidt published a method for quantifying the global cerebral blood flow in humans based on measurements of arteriovenous differences in concentrations of nitrous oxide, a non-metabolized gas [5]. The method solved a problem inherent to earlier attempts of calculating global cerebral blood flow from arteriovenous differences in oxygen concentration. By using an inert gas, the flow could be determined independently from the oxygen metabolism [6]. The inert gas approach, which can be seen as a tracer technique for calculating global cerebral blood flow, led to the development of tracer techniques for imaging regional cerebral blood flow (rCBF). The first method for studying $\mathrm{rCBF}$ was published in 1955 [7]. It was based on intravenously injecting cats with ${ }^{131} \mathrm{I}$-trifluoroiodomethane, an inert gas radioactively labeled with ${ }^{131}$ iodine, and studying the spatial patterns of the flow-dependent wash-in of the gas post-mortem by means of an autoradiographic method. After tracer injection, brains were quickly removed and frozen in order to avoid back-diffusion of the tracer from the brain to plasma. Brain sectioning and autoradiography were performed at $-40^{\circ} \mathrm{C}$ in order to minimize the loss of the volatile compound [6]. By demonstrating the increased blood flow in the visual cortex upon visual stimulation, the method was also the first to provide images of stimulusinduced brain activations $[8,9]$.

Interestingly, it was not generally recognized at that time that these studies formed the basis for what would later be termed "functional neuroimaging." When the data were presented in 1955 on a meeting of the American Neurological Association, Landau (as quoted from [10]) commented: "Of course we recognize that this is a very secondhand way of determining physiological activity; it is rather like trying to measure what a factory does by measuring the intake of water and the output of sewage. This is only a problem of plumbing and only secondary inferences can be made about function. We would not suggest that this is a substitute for electrical recording in terms of easy evaluation of what is going on."

In fact, in terms of spatial and temporal resolution, measurements of blood flow are orders of magnitude apart from electrophysiological recordings. Nevertheless, the following decades clearly showed the usefulness of this approach for 

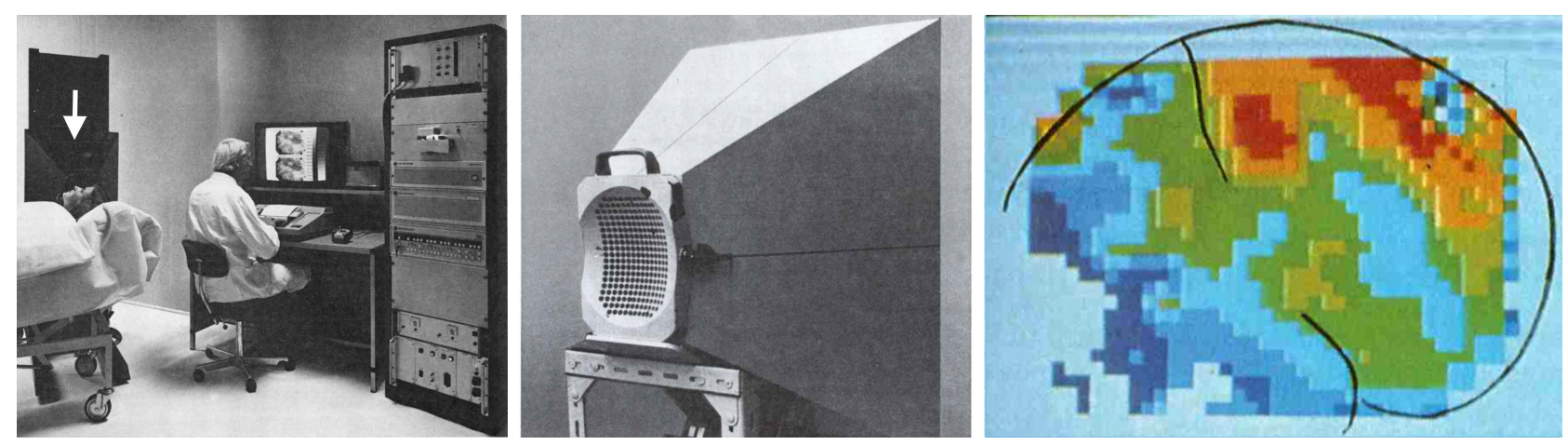

FIGURE 1 | Functional neuroimaging in humans started with 2D scintigraphic imaging of cerebral blood flow. An experimental set-up is shown in the left panel. The arrow points to a gamma camera equipped with a cone beam collimator similar to the collimator shown in the middle panel. The cone-beam collimator is placed close to the subject's head. The gamma camera is a 254 detector camera developed by Per Rommer and Edda Sveinsdottir under the leadership of Niels A. Lassen at Meditronic and commercialized by Medimatic under the name "Dynamatic 254" (Images reprinted with permission from Per Rommer). An example of the images obtained with this set-up is shown in the right panel. Brain contours and the central sulcus are outlined in black. The image shows CBF during hand gripping with the contralateral hand. Reprinted with permission from the American Medical Association. Copyright () (1976) American Medical Association. All rights reserved [12].

detecting spatial patterns of neural activity in experimental animals and in humans. The first images of functional brain activity in humans were 2D scintigraphic gamma camera images from subjects intra-arterially injected with the gamma emitter ${ }^{133} \mathrm{Xe}$ as a tracer, again an inert gas ([11]; Figure 1). Groundbreaking work on functional imaging in humans followed using PET with ${ }^{15} \mathrm{O}-\mathrm{H}_{2} \mathrm{O}$ as a blood flow tracer [1315]. The short half-life of ${ }^{15} \mathrm{O}$ of $2.04 \mathrm{~min}$ made it possible to repeatedly image the same subject inside the PET scanner, and the logic of subtracting data sets from different conditions for studying cognitive processes was introduced [10].

The details of the neurovascular coupling are still under debate. Much progress has been made in elucidating signal cascades coupling energy demands in neural tissue to changes in diameter in capillaries or different segments of the arterial system [16], but the interpretation of increased or decreased flow in volumes of mixed populations of excitatory and inhibitory neurons, presynaptic and post-synaptic neuronal elements, and astrocytes has remained unclear. Under simple conditions, an excitatory input may lead to enhanced post-synaptic processing in a volume element, resulting in an increased flow. Conversely, reduced excitatory input under certain stimulus conditions may result in reduced metabolism and flow appearing as a deactivation. The complexity increases, however, when inhibitory interneurons are involved. Subpopulations of inhibitory interneurons, for instance, may have high firing rates and energy demands, but the net effect on energy demands in a volume element will depend on, among others, the densities of excitatory and inhibitory neurons as well as the local effects of the inhibition, factors that vary in different brain regions.

Stimulus-induced changes in cerebral blood flow as measured with ${ }^{15} \mathrm{O}-\mathrm{H}_{2} \mathrm{O}$ PET in humans increase up to $30 \%$ upon intense stimulation [17]. These changes are relatively large compared to changes in cerebral blood volume (CBV) or in the BOLD response. This may compensate to some degree for the fact that, in contrast to BOLD fMRI or functional ultrasound (fUS) measurements of CBV, usually only one image is taken per individual and condition in CBF studies. Comparisons of the sensitivities of the different methods are difficult, however, as they strongly depend on image noise, which can vary substantially with different imaging protocols and in radionuclide imaging is strongly affected by injected dose and acquisition times.

A number of chemically quite diverse molecules can be used as tracers for imaging cerebral blood flow: inert gases, ${ }^{15} \mathrm{O}-$ labeled water, or labeled lipophilic compounds such as ${ }^{14} \mathrm{C}$ iodoantipyrine [18]. A key feature of all these compounds is that they can readily pass the blood-brain barrier. With all these compounds, the passage through the BBB is bi-directional. In order to measure the blood-flow-dependent wash-in of these compounds into the brain, measurements have to be done quickly after injection-usually within the first minute-as long as there is unidirectional flow of the tracers from plasma to brain. Even if the half-life of ${ }^{15} \mathrm{O}$ were much longer, ${ }^{15} \mathrm{O}-\mathrm{H}_{2} \mathrm{O}$ PET CBF measurements would still have to be done in subjects inside the PET scanner. For autoradiographic measurements in experimental animals, the brains have to be quickly removed after injection [18].

Routine SPECT imaging of CBF differs from these approaches because tracers can be used that are trapped in the brain after passage through the BBB. This makes it possible to image the tracer distributions, or the distributions of the radioactive labels, resp., after trapping. In theory, measurements of CBF using trapped tracers are less straightforward than measurements with inert, non-metabolized compounds, because additional factors come into play, in particular the rates of the trapping reactions and potential redistributions of tracers or trapped labels. In practice, however, the two most commonly used tracers for SPECT imaging of brain perfusion, ${ }^{99 \mathrm{~m}} \mathrm{Tc}-\mathrm{HMPAO}$ [19] and ${ }^{99 \mathrm{~m}}$ Tc-ethyl cysteinate dimer $\left({ }^{99 \mathrm{~m}} \mathrm{Tc}-\mathrm{ECD}\right)$, have been shown to rather accurately reflect CBF [18]. 
Parallelhole-collimator

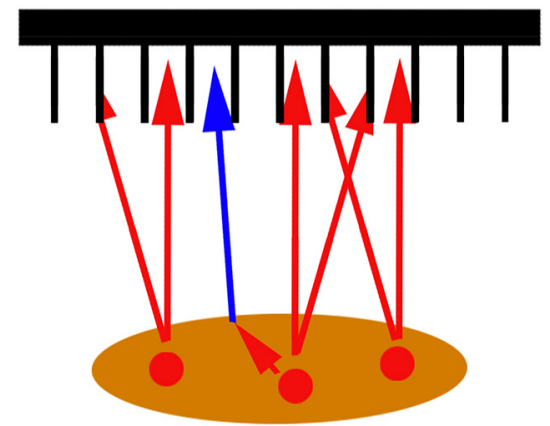

Pinhole-collimator

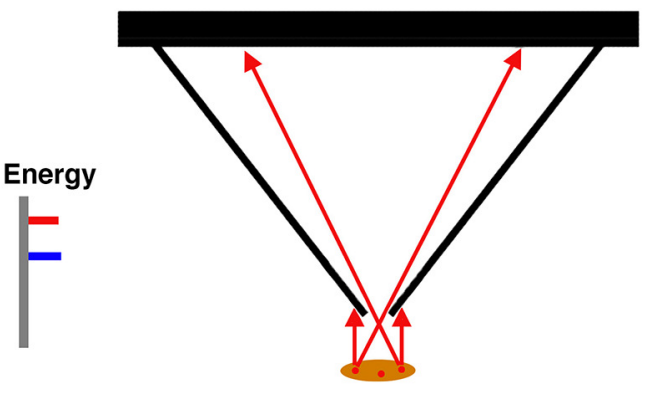

FIGURE 2 | Two collimator types used in SPECT imaging. Parallel-hole collimators, frequently used in SPECT imaging in humans, absorb photons that would reach the detector - within limits - at oblique angles after emission from the sources. The sources are depicted in red. Scattered photons (blue, shown only for the parallel-hole collimator) can be distinguished from non-scattered photons due to their lower energy. When pinhole collimators are used, magnified 2D projection images form on the detector if the imaged objects are close to the pinhole.

Both tracers are trapped by rapid conversion to hydrophilic compounds after passage through the BBB. The available data indicate that ${ }^{99 \mathrm{~m}} \mathrm{Tc}-\mathrm{HMPAO}$ is metabolized to hydrophilic compounds in reactions that, at least in part, depend on glutathione and may take place preferentially in astrocytes [20, 21]. ${ }^{99 m} \mathrm{Tc}-\mathrm{ECD}$ is metabolized to a monoacid form that is retained in brains of primates. ${ }^{99 \mathrm{~m}} \mathrm{Tc}$ is not retained in rat and mouse brains after intravenous ${ }^{99 \mathrm{~m}} \mathrm{Tc}-\mathrm{ECD}$ injections [22, 23]. Studies in mice have shown that the ${ }^{99 \mathrm{~m}} \mathrm{Tc}$ monoacid is quickly extruded by the organic anion transporter OAT3 [24], which is highly expressed in endothelial cells. In addition to the ${ }^{99} \mathrm{~m}$ Tc-labeled tracers, there is also a ${ }^{123}$ I-iodine-labeled tracer available for SPECT imaging, ${ }^{123}$ I-iodoamphetamine ( ${ }^{123}$ I-IMP). In humans, the tracer redistributes already within the first hour after administration [25, 26], a fact that has limited its use. To our knowledge, its redistribution has not been studied with smallanimal SPECT in rodents, but the tracer has been used for an ex vivo SPECT imaging study [27]. Currently, ${ }^{99 \mathrm{~m}} \mathrm{Tc}-\mathrm{HMPAO}$ can be regarded as the tracer of choice for functional neuroimaging using CBF SPECT in rodents.

\section{PRINCIPLES OF SPECT IMAGING IN SMALL ANIMALS}

As mentioned above, the first in vivo images of brain activity were $2 \mathrm{D}$ scintigraphic images of cerebral blood flow in humans with pixel sizes on the order of $1 \mathrm{~cm}^{2}$. These images were taken with a gamma camera, a device developed in the 1950 s by Anger [28, 29].

The traditional Anger camera records the spatial positions and intensities of scintillation events that occur in relatively large crystals-usually flat thallium-activated sodium iodide crystals a few hundred square centimeters in size-upon absorption of gamma photons. In order to relate the spatial position of a scintillation event in the crystal to a restricted volume of possible emission sites in the subject, the cameras are equipped with so-called collimators, a term derived from a false reading of Latin collineare, meaning "to direct in a straight line" (MerriamWebster online dictionary: https://www.merriam-webster.com/ dictionary/collimate).

No different from light emitted from a light source, gamma rays are emitted isotropically from gamma ray sources. Collimators, placed between the sources and the scintillation crystal, limit the possible angles at which gamma rays from different positions in the field of view can reach the crystal (for a review on collimators, see [30]). A parallel-hole collimator, for instance, is a sieve-like structure made of heavy metals that absorbs most of the gamma photons reaching the detector at oblique angles (Figure 2). The 2D projection image of the source distribution is formed from parallel bundles of gamma rays that can pass through the collimator. Absorptive collimation with different collimator geometries is the prevailing method for forming $2 \mathrm{D}$ projection images in SPECT. In general, small fractions of $<1 \%$ of the gamma photons that could theoretically reach the detector pass through the collimator and can be used for image formation [30].

The first systems for 3D imaging of gamma emitters were developed in the 1960s [31, 32]. Scanners with rotating gamma cameras, similar to currently prevailing clinical scanners, were introduced in the 1970s [31]. The development of SPECT imaging was driven not only by advancements in the imaging technology but also by the discovery of the radionuclide ${ }^{99 \mathrm{~m}}$ Technetium [33]. With a physical half-life of $6 \mathrm{~h}$, an energy of the emitted gamma photons of $140 \mathrm{keV}$, which is low enough for efficient detection with $\mathrm{NaI}$-scintillator crystals but high enough for efficient emissions out of the human body, and easy onsite availability from ${ }^{99 \mathrm{~m}} \mathrm{Tc}$ generators, this radionuclide proved to be ideal for SPECT imaging. ${ }^{99 \mathrm{~m}} \mathrm{Tc}$ became the most used radionuclide for diagnostic imaging worldwide [33].

With spatial resolutions in the range of a cubic centimeter in clinical routine, SPECT has been notoriously regarded a low-resolution imaging modality that is inferior to PET in any respect. However, the spatial resolution of SPECT 


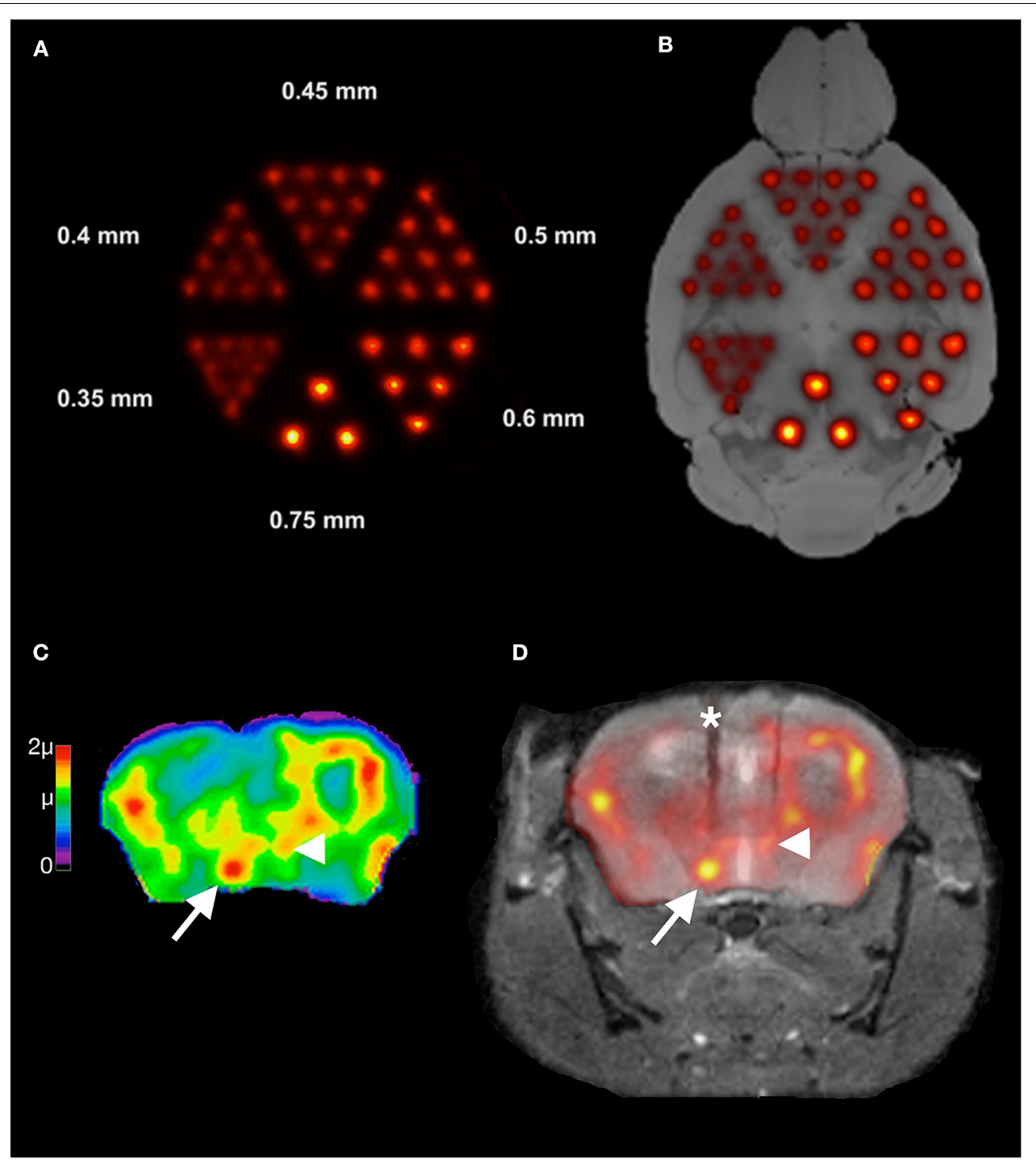

FIGURE 3 | Illustration of spatial resolutions with multi-pinhole SPECT imaging in mouse brain. Shown in (A) is an image of a SPECT measurement of a micro-Jaszczak hot-rod resolution phantom filled with ${ }^{99 \mathrm{~m}} \mathrm{Tc}$. The phantom was scanned with custom-made $0.3 \mathrm{~mm}$ multi-pinhole apertures at the Leibniz Institute for Neurobiology. Rods down to the size of $0.4 \mathrm{~mm}$ can be resolved. In (B), an overlay of the image in (A) onto an anatomical reference MR image [38] of a mouse brain is shown to illustrate these spatial resolutions in relation to the mouse brain anatomy. Resolutions in the range of $0.75 \mathrm{~mm}$ that can easily be achieved in SPECT imaging are already quite useful for imaging brain regional tracer distributions. In (C) a high-resolution ${ }^{99 m}$ TC-HMPAO SPECT image is shown from the CBF of a mouse during intracranial self-stimulation of the medial forebrain bundle ( $\mathrm{mfb}$ ). This image was overlaid on the MR of the same animal in (D). The MR is a post-mortem MR after removal of the self-stimulation setup. The electrode track is marked by an asterisk in (D). Images were taken with the same setup as for the measurement in (A). The color scale in (C) is in units of the global mean intensity $\mu$. Note in (C) the clear delineation of the $\mathrm{mfb}$ (arrow) and the small hypothalamic region with a relatively high uptake (arrowhead).

critically depends on the collimators used and can exceed that of PET.

Magnified projection images of gamma ray sources can be obtained when pinhole collimators (Figure 2) are used, with the magnification depending on pinhole-detector and pinhole-object distances and the resolution depending on pinhole diameters and detector resolutions. High system resolutions can be achieved this way even with detector resolutions in the range of a few millimeters. In principle, microscopic resolutions could be achieved [34], the main limiting factor being the decreasing sensitivity with decreasing pinhole diameter. The system's sensitivity increases with increasing number of pinholes for a given field of view, the maximum number of pinholes depending on the geometries of pinhole and detector arrangements. Current commercially available small-animal SPECT scanners make use of this multi-pinhole technology ([35]; for reviews on smallanimal SPECT, see also [36, 37]; Figure 3). Spatial resolutions down to ca. $250 \mu \mathrm{m}$ have been reported for in vivo imaging [39]. 
These spatial resolutions cannot be achieved in PET imaging of conventional positron emitters in brain tissue. In clinical routine and in most preclinical scanners, PET imaging is based on coincidence detection of two $511 \mathrm{keV}$-photons emitted in nearly opposite directions from positron-electron annihilation sites (but see Walker et al. [40] for a preclinical PET scanner with pinhole collimation). Positrons have to lose most of their kinetic energy before an annihilation event is possible. Annihilation events occur at certain distances from the positron emitting radionuclide or tracer molecules labeled with the radionuclide, a factor limiting the spatial resolution of PET, irrespective of the way the emitted photons are detected. The mean distances between the sites of positron emissions and the sites of annihilations, the so-called positron ranges, depend on the kinetic energies at which positrons are emitted and the probabilities with which the emitted positrons can interact with their environment. On average, positron ranges decrease with increasing tissue density. Positrons emitted from ${ }^{18} \mathrm{~F}$ have a favorably low maximum energy of $0.634 \mathrm{MeV}$ [41], and it seems possible to detect this radionuclide in mouse brain at a spatial resolution close to $600 \mu \mathrm{m}$ [42]. For comparison, ${ }^{15} \mathrm{O}$ emits positrons at a maximum energy of $1.732 \mathrm{MeV}$, resulting in a mean positron range of three millimeters in water [41]. While detection of photons from annihilations rather than detection of photons emitted from radionuclide atoms limits the spatial resolution of PET, there is at the same time a substantial gain in sensitivity when coincidence detection is used, as no collimators are necessary for imaging radionuclide distributions.

In preclinical practice, the spatial resolution advantage of SPECT vs. the sensitivity advantage of PET may in many cases be of minor relevance: Newest-generation small-animal PET scanners approach the fundamental limit in spatial resolution for ${ }^{18} \mathrm{~F}$, which is similar to the resolutions in many routine measurements with small-animal SPECT. On the other hand, SPECT imaging at a resolution of about $700 \mu \mathrm{m}$ is possible with doses that are well within nano- to picomolar ranges. $100 \mathrm{MBq}{ }^{99 \mathrm{~m}} \mathrm{Tc}$ corresponds to ca. 5 pmol (see [43] for details of calculations). With about $1.5 \mathrm{MBq}$ of this amount reaching the mouse brain in a typical CBF imaging experiment [22, 44], this would correspond to ca. $0.075 \mathrm{pmol} / 0.5 \mathrm{~cm}^{3}$ brain tissue corresponding to a concentration of $150 \mathrm{pmol} / \mathrm{L}$ (assuming 1 $\mathrm{cm}^{3}=1 \mathrm{~mL}$ ). For estimating pharmacological or toxicological effects, it has to be taken into account that HMPAO labeled with ${ }^{99} \mathrm{Tc}$, the decay product of ${ }^{99 \mathrm{~m}} \mathrm{Tc}$, also enters the brain. However, even with amounts of ${ }^{99} \mathrm{Tc}-\mathrm{HMPAO}$ exceeding those of ${ }^{99 \mathrm{~m}} \mathrm{Tc}-\mathrm{HMPAO}$ by an order of magnitude, the total concentration of labeled HMPAO would still be outside of the range of pharmacological effects.

In general, the ratio of radioactively labeled tracers vs. tracers labeled with decay products is higher with ${ }^{99 \mathrm{~m}} \mathrm{Tc}$-labeled compounds than with PET tracers because of the longer halflife of ${ }^{99 \mathrm{~m}} \mathrm{Tc}$ and delivery of the radionuclide from ${ }^{99 \mathrm{~m}} \mathrm{Tc}$ generators at high specific activities, i.e., high amounts of radioactive atoms per total number or mass of the atoms. With activities of ${ }^{99 \mathrm{~m}} \mathrm{Tc}$ of $1 \mathrm{GBq}$ delivered in a few hundred microliters of physiological saline solution, volume loads usually are also within limits of good practice for i.v. injections in rodents.

Radionuclide contents can be quantified quite accurately in SPECT and PET imaging if the data sets are corrected for the various factors that affect how many of the emitted photons can finally be counted and selected for 3D image reconstructions, e.g., collimator effects in SPECT, random coincidences in PET, and effects of absorption and scattering in the imaged subjects [45]. Underestimations of the true activities due to gamma ray attenuation in the subjects can be more severe in PET than in SPECT imaging despite the higher photon energies in PET, because a true coincidence event is missing if only one of the two annihilation photons does not reach the detector in a line of response [45]. Without attenuation correction, radionuclide contents would be underestimated in small-animal PET imaging by about $40 \%$ in rats [46] and $20 \%$ in mice [47]. In small-animal SPECT imaging, the combined effects of scattering and absorption can result in underestimations of true activities by about $12 \%$ in mice [ $[48,49]$ and $23 \%$ in rats [50] when using the radionuclide ${ }^{99 \mathrm{~m}} \mathrm{Tc}$. Attenuation correction is computationally simpler in PET imaging $[45,51]$, but algorithms have been developed that reduce the errors in small-animal SPECT imaging to $<5 \%$ [50]. It can be expected that the accuracy will increase further when corrections will be based on calculations of attenuation coefficients from X-ray CT scans or more indirectly from MR images of the same individual, as increasingly done in humans [51]. Finally, when using SPECT for functional neuroimaging in rodents, the focus is on comparing differences in radionuclide distributions in brains from animals of different experimental groups. Due to little variations in brain and skull anatomy, absorption and scattering will also differ little within and between the groups. This tends to reduce attenuation effects in voxel-wise statistical comparisons.

The radionuclide doses given per body weight are generally higher in small-animal imaging as compared with human imaging [52], resulting in higher radiation exposures. Data for ${ }^{99 \mathrm{~m}} \mathrm{Tc}-\mathrm{HMPAO}$ in rats [19] and calculations for other ${ }^{99 \mathrm{~m}} \mathrm{Tc}-$ compounds in mice and rats [52] indicate that whole-body radiation doses in CBF SPECT at commonly used ${ }^{99 \mathrm{~m}} \mathrm{Tc}$ doses, e.g., $100 \mathrm{MBq}$ in mice, can be estimated to be in the lower to mid centigray range, which is well within usual dose ranges in small-animal PET and SPECT imaging [52].

The choice between PET and SPECT in preclinical imaging may frequently depend on scanner availabilities and suitable tracers for the questions to be studied. The logistics of smallanimal SPECT are simpler due to the relatively long half-lives of the radionuclides used. An interesting opportunity in SPECT imaging is dual-isotope SPECT [36, 37]. Two or more tracers can be detected simultaneously if they emit gamma or X-ray photons at energies sufficiently different for being resolved with the detectors used. In principle, images of CBF under two different conditions in the same animal could be obtained by sequentially injecting the two tracers ${ }^{99 \mathrm{~m}} \mathrm{Tc}-\mathrm{HMPAO}$ and ${ }^{123} \mathrm{I}-$ IMP in one session. Because of potential redistributions of ${ }^{123} \mathrm{I}$ IMP, the feasibility of this approach for in vivo imaging is currently unclear, but it could be of interest for high-resolution ex vivo imaging. 

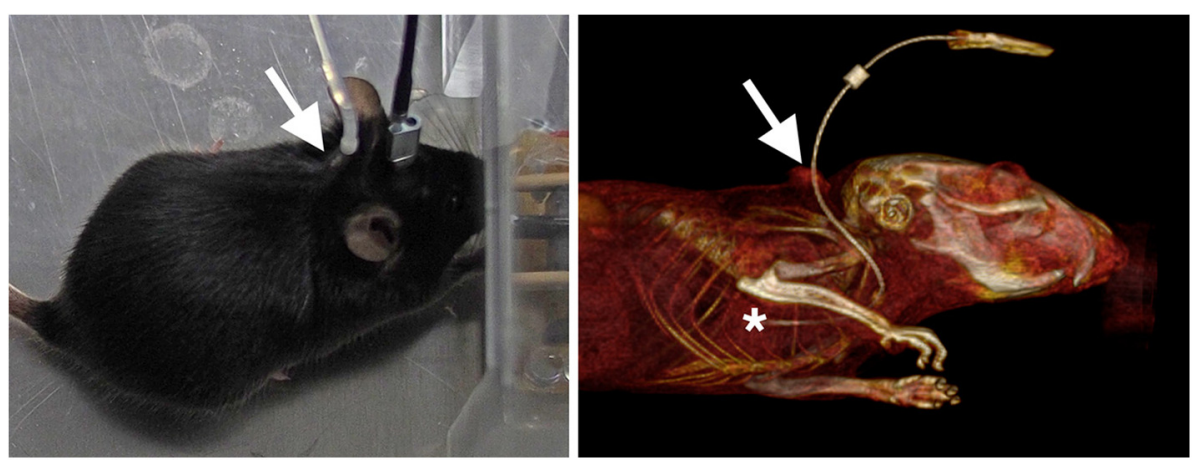

FIGURE 4 | Images of mice implanted with chronic external jugular vein catheters. The image on the left shows a mouse during optogenetic stimulation, the image on the right a volume-rendered CT from a mouse that was injected with an X-ray-dense contrast agent during CT acquisition. The arrows point to the dorsal exit of the catheter. The subcutaneous part of the tunneled catheter can be seen in the CT. The tip of the catheter (asterisk) is at or close to the right atrium.

\section{FUNCTIONAL NEUROIMAGING IN RODENTS USING ${ }^{99 \mathrm{~m}}$ TC-HMPAO SPECT-THE EXPERIMENTAL PROCEDURE}

SPECT imaging of cerebral blood flow in rodents dates back to experiments in the 1990 s in rats $[53,54]$. High-resolution images of cerebral blood flow in mice were demonstrated much later with a multi-pinhole system in 2009 [55].

These experiments were done to demonstrate the spatial resolution of imaging systems using pinhole collimators. ${ }^{99 \mathrm{~m}} \mathrm{Tc}-$ HMPAO was intravenously injected via the tail vein-the common approach of i.v. injections in rodents. The highly lipophilic compound is rapidly cleared from the plasma. Andersen et al. [56] found a high first-pass extraction of about $80 \%$ in rats. The images obtained after a tail vein bolus injection thus mostly represent the mean CBF during the short time span during and shortly after tail vein injection.

In order to make use of the approach for mapping stimulusdependent changes in blood flow, the tracer has to be injected during the stimulation period. To the best of our knowledge, the first study using a dedicated small-animal SPECT scanner for imaging brain activation patterns was performed by Wyckhuys et al. [57] in restrained rats.

For the method to be used for repeated imaging of unrestrained behaving animals, we developed an approach for continuously injecting the tracer during ongoing behavior via catheters in the right external jugular vein. External jugular vein catheterization is a well-established approach for chronic intravenous injections or blood sampling in rodents (for instance [58-67]). From our experience, the complexity of the approach is frequently overestimated. In experienced hands, the surgery takes about $30 \mathrm{~min}$. The catheters are subcutaneously tunneled and exit shortly behind the scapulae (Figure 4). For i.v. injections, the catheters are connected to perfusion pumps via polyethylene tubes with little interference with ongoing behavior. We used this approach in a number of studies including different learning paradigms $[68,69]$.

We have developed a protocol for simple, inexpensive onsite synthesis of ${ }^{99} \mathrm{~m} \mathrm{Tc}-\mathrm{HMPAO}$ close to the behavioral setup [44]. ${ }^{99 \mathrm{~m}} \mathrm{Tc}$ is a so-called generator radionuclide [33]. It is a decay product of ${ }^{99} \mathrm{Mo}-$ molybdenum, a radionuclide with a halflife of 66 hours. ${ }^{99}$ Mo can conveniently be transported over long distances to hospitals for on-site delivery of ${ }^{99 \mathrm{~m}} \mathrm{Tc} .{ }^{99 \mathrm{~m}} \mathrm{Tc}$ generators contain the divalent molybdate anion ${ }^{99} \mathrm{MoO} 4^{2-}$, from which the monovalent pertechnetate anion ${ }^{99 \mathrm{~m}} \mathrm{TcO}_{4}^{-}$ forms when ${ }^{99} \mathrm{Mo}$ decays. The change in valency facilitates separating ${ }^{99} \mathrm{mcO}^{-}$from ${ }^{99} \mathrm{MoO}^{2-}$ by elution with $\mathrm{NaCl}$ solutions. ${ }^{99 \mathrm{~m}} \mathrm{Tc}$ generators are present in practically every department of nuclear medicine. The logistics of supplying a small-animal SPECT lab with ${ }^{99 \mathrm{~m}} \mathrm{Tc}$ are very simple.

For synthesis of ${ }^{99 \mathrm{~m}} \mathrm{Tc}-\mathrm{HMPAO}$, the solution of ${ }^{99 \mathrm{~m}} \mathrm{TcO}^{-}$in saline is added to the organic compound exametazime (HMPAO) in the presence of the reducing agent $\mathrm{Sn}(\mathrm{II}) \mathrm{Cl}_{2}$. HMPAO and $\mathrm{Sn}(\mathrm{II}) \mathrm{Cl}_{2}$ are commercially available as kit preparations delivered as a lyophilized mixture under nitrogen in amounts for use in humans. For use in rodents, we store aliquots of such a kit preparation frozen in saline solutions. Upon use, we add freshly prepared $\mathrm{Sn}(\mathrm{II}) \mathrm{Cl}_{2}$ solution in order to compensate for potential losses due to oxidation during storage [44]. ${ }^{99 \mathrm{~m}} \mathrm{Tc}-\mathrm{HMPAO}$ synthesis from kits or stored aliquots takes a few minutes.

We inject the tracer during ongoing behavior over a period, in most experiments, of about five to $10 \mathrm{~min}$. After injection, animals are anesthetized and scanned (for a scheme of the workflow, see Figure 5). We use co-registered CT scans as anatomical references. In most studies, we repeatedly image the same animals under different behavioral conditions. We use intervals between the measurements of 2 days. For data analysis, we align the SPECT/CTs to reference MRs and calculate parametric voxel-wise statistical maps from global mean normalized data of brain ${ }^{99 \mathrm{~m}} \mathrm{Tc}$ content.

In humans, arterial input functions can be determined and cerebral blood flow or glucose metabolism can be fully quantified 


\section{9mTcO4-elution from generator}

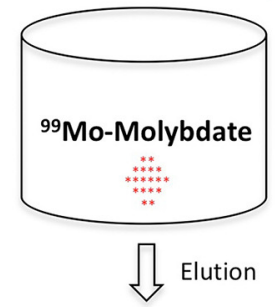

99mTc-Pertechnetate
99mTc-HMPAO synthesis

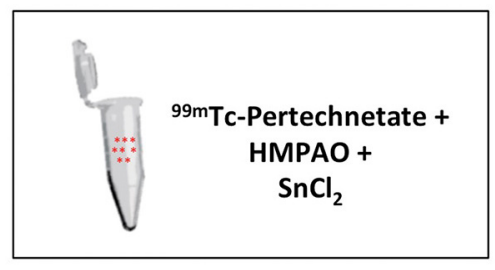

99mTC-HMPAO

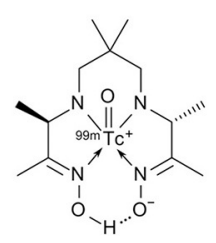

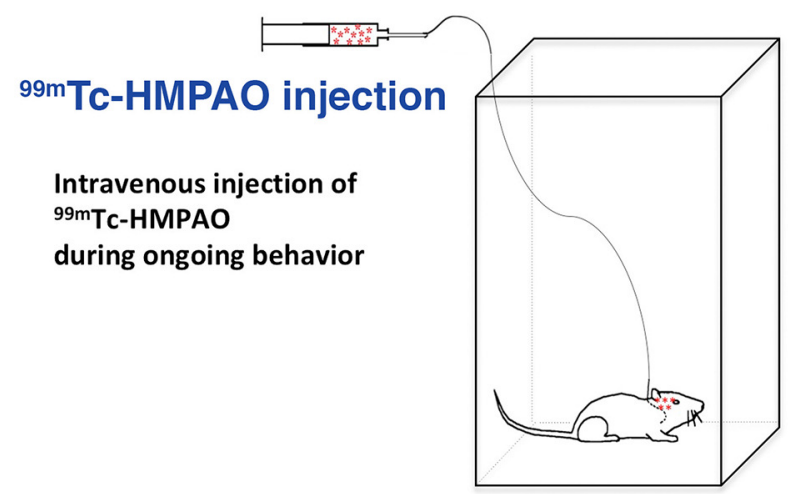
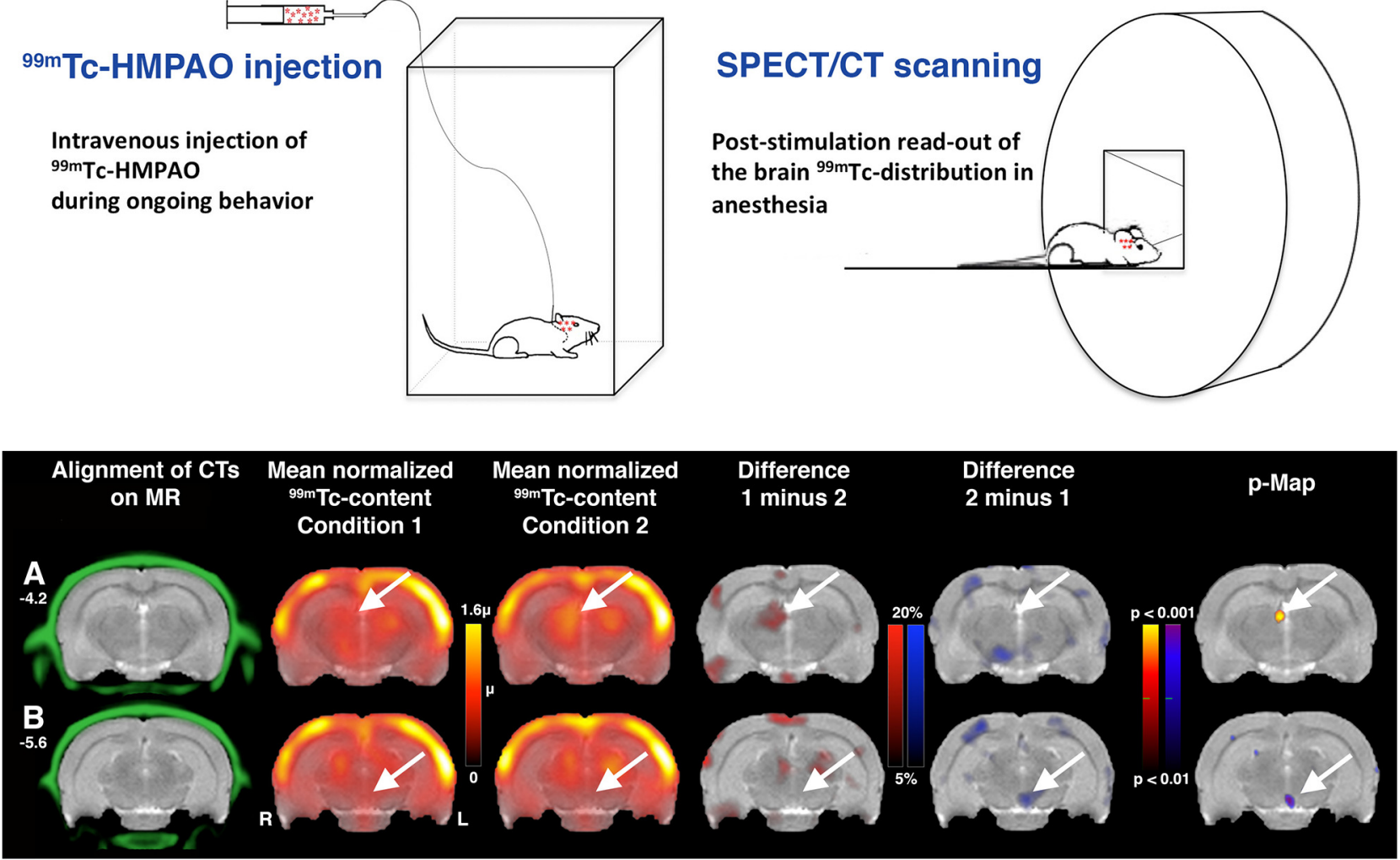

FIGURE 5 | Workflow in functional neuroimaging using ${ }^{99 m}$ Tc-HMPAO SPECT. After elution of ${ }^{99 m}$ Tc-pertechnetate from the ${ }^{99 m}$ Tc generator, ${ }^{99 m}$ Tc-HMPAO can be synthesized on-site in the small-animal SPECT lab. Rodents are intravenously injected with the tracer during ongoing behavior. For SPECT scanning of the distribution of the trapped tracer, the animals are anesthetized. Data analysis starts with aligning of the SPECT data sets to reference MRs or atlases by using the landmarks of the co-registered CT. Here, previously unpublished images from data of a subgroup of rats from the study of innate fear behavior in Vincenz et al. [70] are shown to illustrate the data analysis. Sections at two different Bregma levels are shown (A Bregma -4.2; B Bregma -5.6). The color scale on the left is in units of the global mean intensity. Arrows point to the habenula and interpeduncular nucleus where significant increases or decreases, resp., in flow were found.

with PET imaging. In rodents, and in particular in mice, arterial blood sampling is difficult and impractical in behaving animals. Therefore, intensity normalization is the standard approach to comparing individual and group data in functional smallanimal radionuclide imaging [71, 72]. Especially when used for imaging normal behaving animals, where global metabolic rates and blood flow can be assumed to vary only within narrow limits, the effects of the normalization can be expected to be minor.

\section{CBF SPECT IN THE CONTEXT OF TECHNIQUES FOR IMAGING BRAIN-WIDE ACTIVATION PATTERNS IN AWAKE BEHAVING RODENTS}

We have reviewed above the rationales underlying functional neuroimaging using CBF SPECT in rodents and outlined the experimental procedure that we developed in our lab. We have 
used this approach in a number of different studies including artificial stimulations-electrical as well as optogenetic [44, 73, 74]-pharmacological manipulations [75], studies of baseline metabolism under physiological or pathological conditions [76], or changes in activation patterns due to sensory stimuli in conjunction with [68] or without [70,77] learning paradigms. Our findings matched well with data from other groups using other methods as far as such data were available. The involvement of the habenulo-interpeduncular system in innate fear behavior [70], for instance, or of the supramammillary nucleus in food reward [75] as described in our SPECT studies has also been found with optogenetic or electrophysiological methods, resp. [78-80].

The scope of most of our studies was on screening for brainwide activation patterns in behaving rodents. Many of these studies would have been very difficult or impossible to perform with BOLD fMRI, especially those that require active locomotor behaviors as the intracranial self-stimulation studies or studies with complex learning paradigms [68].

Some of the studies might have been performed with ${ }^{18} \mathrm{~F}-\mathrm{FDG}$ PET. In fact, the scopes of applications of ${ }^{18}$ F-FDG PET (see, for instance, $[71,72,81-83])$ and ${ }^{99 \mathrm{~m}} \mathrm{Tc}$-HMPAO SPECT are very similar. As mentioned above, both methods provide static images of spatial patterns of neural activity averaged or integrated resp. over certain periods of time. However, due to differences in tracer kinetics, the integration times differ considerably between the two methods.

As studied in detail by Sokoloff et al. when they introduced the autoradiographic technique for mapping cerebral glucose metabolism using 2-deoxyglucose (2-DG) labeled with ${ }^{14} \mathrm{C}$, it takes about $30-45 \mathrm{~min}$ until, after a single bolus injection, sufficient amounts of the tracer are trapped in the brain [84]. 2-DG can enter and leave the brain via facilitated diffusion through glucose transporters in the BBB. The brain regional 2DG distribution shortly after injection reflects spatial patterns of 2-DG influx in relation to blood flow. In a relatively slow process, 2-DG is phosphorylated to 2-DG-6-phosphate, which is trapped intracellularly and does not redistribute. Images taken earlier than about 30 min reflect to varying degrees the influx, efflux, and phosphorylation of 2-DG. In order to image with ${ }^{18}$ F-FDG PET a tracer distribution that solely or at least largely reflects tracer uptake and phosphorylation in the unrestrained awake state outside the scanner and that remains stable during subsequent image acquisition under anesthesia inside the scanner, animals cannot be imaged much earlier than about $30 \mathrm{~min}$ after ${ }^{18} \mathrm{~F}$ FDG injection.

On the other hand, the long uptake and phosphorylation times of ${ }^{18} \mathrm{~F}$-FDG make it possible to inject a single tracer dose i.v. or i.p. before the behavioral experiment starts. Repeated imaging of the same individual over long time periods such as weeks or months is easier with ${ }^{18} \mathrm{~F}-\mathrm{FDG}$ because there is no need for implanting intravenous catheters.

In contrast to ${ }^{18} \mathrm{~F}-\mathrm{FDG},{ }^{99 \mathrm{~m}} \mathrm{Tc}-\mathrm{HMPAO}$ is rapidly cleared from the plasma and rapidly trapped in the brain. We mentioned above the high first-pass extraction of about $80 \%$ [56]. In humans, count rates in the brain reach maximum values $30-40 \mathrm{~s}$ after injection, then decrease slightly to $91 \%$ and remain constant
2 min after injection [85]. The 40-s period until the net uptake of ${ }^{99 \mathrm{~m}} \mathrm{Tc}-\mathrm{HMPAO}$ ceases can be seen as the maximum temporal resolution that might theoretically be achieved when using CBF SPECT for assessing the spatial patterns of neural activity in unrestrained animals outside scanner environments, the limiting factor in practice being the volume load if the dose necessary for imaging at high resolution and high signal-to-noise ratio should be injected in one single bolus. In our routine protocols, we use time spans of several minutes over which ${ }^{99 \mathrm{~m}} \mathrm{Tc}$-HMPAO is injected. The time spans might be adjusted to the behavioral paradigms under study.

Among the different tracer techniques for in vivo imaging of brain-wide activation patterns in rodents, the highest spatial resolution can be achieved with MEMRI [86], but without opening the $\mathrm{BBB}$, manganese reaches detectable levels only slowly. The long stimulation times on the order of several hours limit the scope of applications.

The static images that are usually acquired with all of these tracer techniques provide insight into temporal dynamics only insofar as the temporal dynamics might affect the average spatial patterns of network activities. In theory, nuclear imaging techniques are well-suited for imaging temporal dynamics. Motion-correction algorithms have been used to obtain images of awake behaving animals inside scanners [87-89], and miniaturized, wearable PET scanners for brain imaging in behaving rats have been developed [90]. The methods can be of high value for imaging tracers that are not trapped and the distribution of which might change under anesthesia as compared with that in the awake state, e.g., neurotransmitter receptor ligands. Imaging at both high spatial resolutions and short acquisition times in the range of seconds or lower would require high sensitivities and/or high radionuclide doses and might be challenging. It remains to be seen whether approaches for $4 \mathrm{D}$ functional neuroimaging in awake behaving rodents, based on imaging, e.g., CBF, CBV, or displacement of receptor ligands, might emerge from nuclear imaging techniques and what spatial and temporal resolutions these could provide.

Four-dimensional whole-brain imaging of spatiotemporal patterns of neural activity in behaving rodents is possible with ultrasound imaging of changes in CBV [91]. As a major drawback compared to fMRI, PET, and SPECT, animals have to undergo skull surgery in order to enable ultrasound imaging. Measurements have been performed through the thinned skull in rats [92], ultrasound-clear skull prostheses [93], or large cranial windows in head-fixed mice [94]. In the latter study [94], high spatial resolutions of about $100 \mu \mathrm{m}$ in-plane and $300 \mu \mathrm{m}$ offplane have been obtained, but relatively long imaging times were used ranging from $14 \mathrm{~min}$ to several hours.

In the context of the array of in vivo whole-brain functional neuroimaging techniques, we see the attractiveness of functional CBF SPECT imaging in the combination of minimal invasiveness with relatively high spatial resolution and simple logistics.

The temporal resolution might be improved with stimulustriggered short bolus injections of ${ }^{99 \mathrm{~m}} \mathrm{Tc}-\mathrm{HMPAO}$, but it certainly cannot compete with that of BOLD fMRI. When effects of anesthesia or restraints can be tolerated or expected to be minor, BOLD fMRI is certainly the method of choice. 
From the underlying physics, the spatial resolution of ${ }^{99 \mathrm{~m}} \mathrm{Tc}$ HMPAO SPECT could be further increased, the limiting factor in practice being the limited sensitivity that, to our experience, can make imaging well-beyond the range of about $500 \mu \mathrm{m}$ difficult for routine use, as it requires injections of large doses or volumes resp. and/or long scan times. It remains to be seen whether technical improvements could increase the sensitivity in smallanimal SPECT imaging.

Despite the variety of new methods for in vivo imaging of neural activity, there are still only three approaches to noninvasively-in particular without the need for head surgeryobtain images of brain-wide patterns of neural activity in awake unrestrained rodents, ${ }^{18} \mathrm{~F}-\mathrm{FDG}$ PET, MEMRI, and ${ }^{99 \mathrm{~m}} \mathrm{Tc}$ HMPAO SPECT. Currently, the vast majority of studies aiming at elucidating brain-wide patterns of neural activity in rodents are done by post-mortem readout of the patterns of immediate early genes (IEGs) expressed in an activity-dependent manner in vivo [95]. IEG expression patterns can be mapped with cellular resolution, but data acquisition and analysis are time consuming. Similar to tracer techniques, IEG mapping studies provide little information on temporal dynamics on timescales of neuronal signal-processing rates, but the decades of its use demonstrate at the same time the value of this spatial information for elucidating network activation patterns.

Within this array of methods for imaging brain-wide spatial patterns of neural activity in unrestrained rodents, ${ }^{99 \mathrm{~m}} \mathrm{Tc}-\mathrm{HMPAO}$ SPECT is, in our opinion, a highly attractive technique. When aiming at regional spatial resolutions, it

\section{REFERENCES}

1. Venkatachalam V, Ji N, Wang X, Clark C, Mitchell JK, Klein M, et al. Panneuronal imaging in roaming Caenorhabditis elegans. Proc Natl Acad Sci USA. (2016) 113:E1082-8. doi: 10.1073/pnas.1507109113

2. Vanwalleghem GC, Ahrens MB, Scott EK. Integrative whole-brain neuroscience in larval zebrafish. Curr Opin Neurobiol. (2018) 50:136-45. doi: 10.1016/j.conb.2018.02.004

3. Vetere G, Kenney JW, Tran LM, Xia F, Steadman PE, Parkinson J, et al. Chemogenetic interrogation of a brain-wide fear memory network in mice. Neuron. (2017) 94:363-74.e4. doi: 10.1016/j.neuron.2017.03.037

4. Herculano-Houzel S, Mota B, Lent R. Cellular scaling rules for rodent brains. Proc Natl Acad Sci USA. (2006) 103:12138-43. doi: 10.1073/pnas.0604911103

5. Kety SS, Schmidt CF. The nitrous oxide method for the quantitative determination of cerebral blood flow in man: theory, procedure and normal values. J Clin Invest. (1948) 27:476-83. doi: 10.1172/JCI101994

6. Kety SS. The measurement of cerebral blood flow by means of inert diffusible tracers. Keio J Med. (1994) 43:9-14. doi: 10.2302/kjm.43.9

7. Landau WM, Freygang WH Jr, Roland LP, Sokoloff L, Kety SS. The local circulation of the living brain; values in the unanesthetized and anesthetized cat. in: 80th Meeting Trans Am Neurol Assoc. (1955) 125-9.

8. Sokoloff L. Local cerebral circulation at rest and during altered cerebral activity induced by anesthesia or visual stimulation. In: SS Kety, J Elkes, editors. The Regional Chemistry, Physiology and Pharmacology of the Nervous System Oxford: Pergamon Press (1961). p. 107-17.

9. Sokoloff L. Preface to volume 1. In: Squire LR, editor. The History of Neuroscience in Autobiography. Washington, DC: Library of Congress Catalog Card Number 96-709501996 (2005). p. 454-97.

10. Raichle ME. Behind the scenes of functional brain imaging: a historical and physiological perspective. Proc Natl Acad Sci USA. (1998) 95:765-72. doi: 10.1073/pnas.95.3.765 provides 3D data sets of functional brain activations at substantially higher throughput than IEG-mapping approaches, and stimulation times in the minute range make the method less sensitive to the effects of behavioral habituation than ${ }^{18} \mathrm{~F}-\mathrm{FDG}$ PET and MEMRI.

\section{ETHICS STATEMENT}

All experiments were conducted according to the guidelines of the European Community (Directive 2010/63/EU) and approved by a local ethics committee of the Federal state of Saxony-Anhalt.

\section{AUTHOR CONTRIBUTIONS}

JG and AO conceived the review and wrote the manuscript.

\section{FUNDING}

This work was supported by the German Federal Ministry of Education and Science (BMBF grants 01SF0718 and 03 V0765) and the Deutsche Forschungsgemeinschaft (SFB 779). The publication of this article was funded by the Open Access Fund of the Leibniz Association.

\section{ACKNOWLEDGMENTS}

The authors wish to thank Frank Angenstein for providing the MR image in Figure 3D.
11. Lassen NA, Ingvar DH, Skinhoj E. Brain function and blood flow. Sci Am. (1978) 239:62-71. doi: 10.1038/scientificamerican1078-62

12. Roland PE, Larsen B. Focal increase of cerebral blood flow during stereognostic testing in man. Arch Neurol. (1976) 33:551-8. doi: 10.1001/archneur.1976.00500080029005

13. Fox PT, Mintun MA, Raichle ME, Miezin FM, Allman JM, Van Essen DC. Mapping human visual cortex with positron emission tomography. Nature. (1986) 323:806-9. doi: 10.1038/323806a0

14. Herscovitch P, Markham J, Raichle ME. Brain blood flow measured with intravenous H2O. I. Theory and error analysis. J Nucl Med. (1983) 24:782-9.

15. Raichle ME, Martin WR, Herscovitch P, Mintun MA, Markham J. Brain blood flow measured with intravenous $\mathrm{H}_{2} \mathrm{O}$. II. Implementation and validation. $J$ Nucl Med. (1983) 24:790-8.

16. Iadecola C. The neurovascular unit coming of age: a journey through neurovascular coupling in health and disease. Neuron. (2017) 96:17-42. doi: 10.1016/j.neuron.2017.07.030

17. Fox PT, Raichle ME. Stimulus rate dependence of regional cerebral blood flow in human striate cortex, demonstrated by positron emission tomography. J Neurophysiol. (1984) 51:1109-20. doi: 10.1152/jn.1984.51. 5.1109

18. Holschneider DP, Maarek JM. Mapping brain function in freely moving subjects. Neurosci Biobehav Rev. (2004) 28:449-61. doi: 10.1016/j.neubiorev.2004.06.007

19. Neirinckx RD, Canning LR, Piper IM, Nowotnik DP, Pickett RD, Holmes RA, et al. Technetium-99m d,l-HM-PAO: a new radiopharmaceutical for SPECT imaging of regional cerebral blood perfusion. J Nucl Med. (1987) 28:191-202.

20. Neirinckx RD, Burke JF, Harrison RC, Forster AM, Andersen AR, Lassen NA. The retention mechanism of technetium-99m-HM-PAO: intracellular reaction with glutathione. J Cereb Blood Flow Metab. (1988) 8:S4-12. doi: $10.1038 / \mathrm{jcbfm} .1988 .27$ 
21. Zerarka S, Pellerin L, Slosman D, Magistretti PJ. Astrocytes as a predominant cellular site of (99m)Tc-HMPAO retention. J Cereb Blood Flow Metab. (2001) 21:456-68. doi: 10.1097/00004647-200104000-00014

22. Apostolova I, Wunder A, Dirnagl U, Michel R, Stemmer N, Lukas M, et al. Brain perfusion SPECT in the mouse: normal pattern according to gender and age. Neuroimage. (2012) 63:1807-17. doi: 10.1016/j.neuroimage.2012.08.038

23. Inoue $\mathrm{Y}$, Momose $\mathrm{T}$, Ohtake $\mathrm{T}$, Nishikawa $\mathrm{J}$, Sasaki $\mathrm{Y}$, Waritani $\mathrm{T}$, et al. Metabolism of technetium-99m-L,L-ethyl cysteinate dimer in rat and cynomolgus monkey tissue. J Nucl Med. (1997) 38:1731-7.

24. Kikuchi T, Okamura T, Wakizaka H, Okada M, Odaka K, Yui J, et al. OAT3-mediated extrusion of the $99 \mathrm{mTc}-\mathrm{ECD}$ metabolite in the mouse brain. J Cereb Blood Flow Metab. (2014) 34:585-8. doi: 10.1038/jcbfm. 2014.20

25. Creutzig H, Schober O, Gielow P, Friedrich R, Becker H, Dietz H, et al. Cerebral dynamics of N-isopropyl-(123I)p-iodoamphetamine. J Nucl Med. (1986) 27:178-83.

26. Yonekura Y, Nishizawa S, Mukai T, Iwasaki Y, Fukuyama H, Ishikawa M, et al. Functional mapping of flow and back-diffusion rate of N-isopropyl-piodoamphetamine in human brain. J Nucl Med. (1993) 34:839-44.

27. Zeniya T, Watabe H, Hayashi T, Ose T, Myojin K, Taguchi A, et al. Threedimensional quantitation of regional cerebral blood flow in mice using a highresolution pinhole SPECT system and 123I-iodoamphetamine. Nucl Med Biol. (2011) 38:1157-64. doi: 10.1016/j.nucmedbio.2011.04.007

28. Anger HO. Use of a Gamma-Ray Pinhole Camera for in vivo Studies. Nature. (1952) 170:200-1. doi: 10.1038/170200b0

29. Anger HO. Scintillation Camera. Rev Sci Instr. (1958) 29:27-33. doi: $10.1063 / 1.1715998$

30. Van Audenhaege K, Van Holen R, Vandenberghe S, Vanhove C, Metzler SD, Moore SC. Review of SPECT collimator selection, optimization, and fabrication for clinical and preclinical imaging. Med Phys. (2015) 42:4796813. doi: 10.1118/1.4927061

31. Hutton BF. The origins of SPECT and SPECT/CT. Eur J Nucl Med Mol Imaging. (2014) 41(Suppl. 1):S3-16. doi: 10.1007/s00259-013-2606-5

32. Kuhl DE, Edwards RQ. Image separation radioisotope scanning. Radiology. (1963) 80:653-62. doi: 10.1148/80.4.653

33. Eckelman WC. Unparalleled contribution of technetium- $99 \mathrm{~m}$ to medicine over 5 decades. JACC Cardiovasc Imaging. (2009) 2:364-8. doi: 10.1016/j.jcmg.2008.12.013

34. Beekman F, van der Have F. The pinhole: gateway to ultra-high-resolution three-dimensional radionuclide imaging. Eur J Nucl Med Mol Imaging. (2007) 34:151-61. doi: 10.1007/s00259-006-0248-6

35. Deleye S, Van Holen R, Verhaeghe J, Vandenberghe S, Stroobants S, Staelens S. Performance evaluation of small-animal multipinhole muSPECT scanners for mouse imaging. Eur J Nucl Med Mol Imaging. (2013) 40:744-58. doi: 10.1007/s00259-012-2326-2

36. Bernsen MR, Vaissier PE, Van Holen R, Booij J, Beekman FJ, de Jong M. The role of preclinical SPECT in oncological and neurological research in combination with either CT or MRI. Eur J Nucl Med Mol Imaging. (2014) 41(Suppl. 1):S36-49. doi: 10.1007/s00259-013-2685-3

37. Franc BL, Acton PD, Mari C, Hasegawa BH. Small-animal SPECT and SPECT/CT: important tools for preclinical investigation. J Nucl Med. (2008) 49:1651-63. doi: 10.2967/jnumed.108.055442

38. Ma Y, Hof PR, Grant SC, Blackband SJ, Bennett R, Slatest L, et al. A three-dimensional digital atlas database of the adult C57BL/6J mouse brain by magnetic resonance microscopy. Neuroscience. (2005) 135:1203-15. doi: 10.1016/j.neuroscience.2005.07.014

39. Ivashchenko O, van der Have F, Villena JL, Groen HC, Ramakers $\mathrm{RM}$, Weinans $\mathrm{HH}$, et al. Quarter-millimeter-resolution molecular mouse imaging with U-SPECT(+). Mol Imaging. (2014) 13:1-8. doi: 10.2310/7290.2014.00053

40. Walker MD, Goorden MC, Dinelle K, Ramakers RM, Blinder S, Shirmohammad M, et al. Performance assessment of a preclinical PET scanner with pinhole collimation by comparison to a coincidencebased small-animal PET scanner. J Nucl Med. (2014) 55:1368-74. doi: 10.2967/jnumed.113.136663

41. Conti M, Eriksson L. Physics of pure and non-pure positron emitters for PET: a review and a discussion. EJNMMI Phys. (2016) 3:8. doi: $10.1186 /$ s40658-016-0144-5
42. Yang Y, Bec J, Zhou J, Zhang M, Judenhofer MS, Bai X, et al. A prototype high-resolution small-animal PET scanner dedicated to mouse brain imaging. J Nucl Med. (2016) 57:1130-5. doi: 10.2967/jnumed.115.165886

43. Zolle I. Performance and Quality Control of the $99 \mathrm{Mo} / 99 \mathrm{mTc}$ Generator. In: Zolle I, editor. Technetium-99m Pharmaceuticals, Preparation and Quality Control in Nuclear Medicine. 1 ed. Berlin; Heidelberg: Springer-Verlag (2007). p. 345 .

44. Kolodziej A, Lippert M, Angenstein F, Neubert J, Pethe A, Grosser OS, et al. SPECT-imaging of activity-dependent changes in regional cerebral blood flow induced by electrical and optogenetic self-stimulation in mice. Neuroimage. (2014) 103:171-80. doi: 10.1016/j.neuroimage.2014.09.023

45. Bushberg JT, Seibert JA, Boone JM, Leidholdt EM. The Essential Physics of Medical Imaging. 3rd ed. Philadelphia, PA: Wolters Kluwer Health/Lippincott Williams \& Wilkins (2012) p. 705-47.

46. D’Ambrosio D, Zagni F, Spinelli AE, Marengo M. Attenuation correction for small animal PET images: a comparison of two methods. Comput Math Methods Med. (2013) 2013:103476. doi: 10.1155/2013/103476

47. El Ali HH, Bodholdt RP, Jorgensen JT, Myschetzky R, Kjaer A. Importance of Attenuation Correction (AC) for small animal pet imaging. Diagnostics. (2012) 2:42-51. doi: 10.3390/diagnostics2040042

48. Austin DW, Feng B, Mintzer RA, Chen M, Gregor J, Stuckey A, et al. Validation of CT-based attenuation correction for multi-pinhole PSF reconstruction for small-animal SPECT. In: IEEE Nuclear Science Symposium Conference Record Nuclear Science Symposium. Knoxville, TN (2010). p. 333942. doi: 10.1109/NSSMIC.2010.5874423

49. Finucane CM, Murray I, Sosabowski JK, Foster JM, Mather SJ. Quantitative accuracy of low-count SPECT imaging in phantom and in vivo mouse studies. Int J Mol Imaging. (2011) 2011:197381. doi: 10.1155/2011/197381

50. Gerdekoohi SK, Vosoughi N, Tanha K, Assadi M, Ghafarian P, Rahmim A, et al. Implementation of absolute quantification in small-animal SPECT imaging: phantom and animal studies. J Appl Clin Med Phys. (2017) 18:21523. doi: $10.1002 / \mathrm{acm} 2.12094$

51. Lee TC, Alessio AM, Miyaoka RM, Kinahan PE. Morphology supporting function: attenuation correction for SPECT/CT, PET/CT, and PET/MR imaging. Q J Nucl Med Mol Imaging. (2016) 60:25-39.

52. Funk T. Sun M, Hasegawa BH. Radiation dose estimate in small animal SPECT and PET. Med Phys. (2004) 31:2680-6. doi: 10.1118/1.1781553

53. Ishizu K, Mukai T, Yonekura Y, Pagani M, Fujita T, Magata Y, et al. Ultrahigh resolution SPECT system using four pinhole collimators for small animal Studies. J Nuclear Med. (1995) 36:2282-7.

54. Weber DA, Ivanovic M, Franceschi D, Strand SE, Erlandsson K, Franceschi M, et al. Pinhole SPECT: an approach to in vivo high resolution SPECT imaging in small laboratory animals. J Nucl Med. (1994) 35:342-8.

55. Pissarek M, Meyer-Kirchrath J, Hohlfeld T, Vollmar S, Oros-Peusquens AM, Flogel $\mathrm{U}$, et al. Targeting murine heart and brain: visualisation conditions for multi-pinhole SPECT with (99m)Tc- and (123)I-labelled probes. Eur J Nucl Med Mol Imaging. (2009) 36:1495-509. doi: 10.1007/s00259-009-1142-9

56. Andersen AR, Friberg H, Knudsen KB, Barry DI, Paulson OB, Schmidt JF, et al. Extraction of [99mTc]-d,l-HM-PAO across the blood-brain barrier. J Cereb Blood Flow Metab. (1988) 8:S44-51. doi: 10.1038/jcbfm.1988.32

57. Wyckhuys T, Staelens S, Van Nieuwenhuyse B, Deleye S, Hallez H, Vonck $\mathrm{K}$, et al. Hippocampal deep brain stimulation induces decreased $\mathrm{rCBF}$ in the hippocampal formation of the rat. Neuroimage. (2010) 52:55-61. doi: 10.1016/j.neuroimage.2010.04.017

58. Bardelmeijer HA, Buckle T, Ouwehand M, Beijnen JH, Schellens JH, van Tellingen $\mathrm{O}$. Cannulation of the jugular vein in mice: a method for serial withdrawal of blood samples. Lab Anim. (2003) 37:181-7. doi: 10.1258/002367703766453010

59. De Luca T, Szilagyi KL, Hargreaves KA, Collins KS, Benson EA. Improving the patency of jugular vein catheters in Sprague-Dawley rats by using an antiseptic nitrocellulose coating. J Am Assoc Lab Anim Sci. (2018) 57:520-8. doi: 10.30802/AALAS-JAALAS-18-000017

60. Feng J, Fitz Y, Li Y, Fernandez M, Cortes Puch I, Wang D, et al. Catheterization of the carotid artery and jugular vein to perform hemodynamic measures, infusions and blood sampling in a conscious rat model. J Vis Exp. (2015) 2015:51881. doi: 10.3791/51881

61. Gaud N, Kumar A, Matta M, Kole P, Sridhar S, Mandlekar S, et al. Single jugular vein cannulated rats may not be suitable for intravenous 
pharmacokinetic screening of high $\log P$ compounds. Eur J Pharm Sci. (2017) 99:272-8. doi: 10.1016/j.ejps.2016.12.025

62. Park AY, Plotsky PM, Pham TD, Pacak K, Wynne BM, Wall SM, et al. Blood collection in unstressed, conscious, and freely moving mice through implantation of catheters in the jugular vein: a new simplified protocol. Physiol Rep. (2018) 6:e13904. doi: 10.14814/phy2.13904

63. Thrivikraman KV, Huot RL, Plotsky PM. Jugular vein catheterization for repeated blood sampling in the unrestrained conscious rat. Brain Res Brain Res Protoc. (2002) 10:84-94. doi: 10.1016/S1385-299X(02)00185-X

64. Onishi S, Kaji T, Machigashira S, Yamada W, Masuya R, Nakame K, et al. The effect of intravenous lipid emulsions and mucosal adaptation following massive bowel resection. J Pediatr Surg. (2018) 53:2444-8. doi: 10.1016/j.jpedsurg.2018.08.019

65. Wang T, Liu C, Wei P, Lv L, Yang Z. The inhibiting effect of intravenous anesthesia on adrenal gland functions under the sepsis condition. Int $J$ Immunopathol Pharmacol. (2017) 30:188-93. doi: 10.1177/0394632017705049

66. Yamada W, Kaji T, Onishi S, Nakame K, Yamada K, Kawano T, et al. Ghrelin improves intestinal mucosal atrophy during parenteral nutrition: an experimental study. J Pediatr Surg. (2016) 51:2039-43. doi: 10.1016/j.jpedsurg.2016.09.035

67. Zhang Y, Li RM, Wang C, Liu N, Lv S, Xiong JY. Etomidate inhibits nuclear factor-kappaB through decreased expression of glucocorticoid receptor in septic rats. Mol Med Rep. (2016) 14:5760-6. doi: 10.3892/mmr.2016.5947

68. Bhattacharya S, Herrera-Molina R, Sabanov V, Ahmed $T$, Iscru E, Stober F, et al. Genetically induced retrograde amnesia of associative memories after neuroplastin ablation. Biol Psychiatry. (2017) 81:124-35. doi: 10.1016/j.biopsych.2016.03.2107

69. Mannewitz A, Bock J, Kreitz S, Hess A, Goldschmidt J, Scheich H, et al. Comparing brain activity patterns during spontaneous exploratory and cueinstructed learning using single photon-emission computed tomography (SPECT) imaging of regional cerebral blood flow in freely behaving rats. Brain Struct Funct. (2018) 223:2025-38. doi: 10.1007/s00429-017-1605-x

70. Vincenz D, Wernecke KEA, Fendt M, Goldschmidt J. Habenula and interpeduncular nucleus differentially modulate predator odor-induced innate fear behavior in rats. Behav Brain Res. (2017) 332:164-71. doi: 10.1016/j.bbr.2017.05.053

71. Endepols H, Sommer S, Backes H, Wiedermann D, Graf R, Hauber W. Effort-based decision making in the rat: an [18F]fluorodeoxyglucose micro positron emission tomography study. J Neurosci. (2010) 30:9708-14. doi: 10.1523/JNEUROSCI.1202-10.2010

72. Thanos PK, Robison L, Nestler EJ, Kim R, Michaelides M, Lobo $\mathrm{MK}$, et al. Mapping brain metabolic connectivity in awake rats with muPET and optogenetic stimulation. J Neurosci. (2013) 33:6343-9. doi: 10.1523/JNEUROSCI.4997-12.2013

73. Brocka M, Helbing C, Vincenz D, Scherf T, Montag D, Goldschmidt J, et al. Contributions of dopaminergic and non-dopaminergic neurons to VTA-stimulation induced neurovascular responses in brain reward circuits. Neuroimage. (2018) 177:88-97. doi: 10.1016/j.neuroimage.2018.04.059

74. Weidner TC, Vincenz D, Brocka M, Tegtmeier J, Oelschlegel AM, Ohl FW, et al. Matching stimulation paradigms resolve apparent differences between optogenetic and electrical VTA stimulation. Brain Stimul. (2019) 13:363-71. doi: 10.1016/j.brs.2019.11.005

75. Vogel H, Wolf S, Rabasa C, Rodriguez-Pacheco F, Babaei CS, Stober F, et al. GLP-1 and estrogen conjugate acts in the supramammillary nucleus to reduce food-reward and body weight. Neuropharmacology. (2016) 110:396406. doi: 10.1016/j.neuropharm.2016.07.039

76. Pottker B, Stober F, Hummel R, Angenstein F, Radyushkin K, Goldschmidt J, et al. Traumatic brain injury causes long-term behavioral changes related to region-specific increases of cerebral blood flow. Brain Struct Funct. (2017) 222:4005-21. doi: 10.1007/s00429-017-1452-9

77. Henschke JU, Oelschlegel AM, Angenstein F, Ohl FW, Goldschmidt J, Kanold PO, et al. Early sensory experience influences the development of multisensory thalamocortical and intracortical connections of primary sensory cortices. Brain Struct Funct. (2018) 223:1165-90. doi: 10.1007/s00429-017-1549-1

78. Le May MV, Hume C, Sabatier N, Schele E, Bake T, Bergstrom U, et al. Activation of the rat hypothalamic supramammillary nucleus by food anticipation, food restriction or ghrelin administration. J Neuroendocrinol. (2019) 31:e12676. doi: 10.1111/jne.12676
79. Yang H, Yang J, Xi W, Hao S, Luo B, He X, et al. Laterodorsal tegmentum interneuron subtypes oppositely regulate olfactory cue-induced innate fear. Nat Neurosci. (2016) 19:283-9. doi: 10.1038/nn.4208

80. Zhang J, Tan L, Ren Y, Liang J, Lin R, Feng Q, et al. Presynaptic excitation via $G A B A B$ receptors in Habenula cholinergic neurons regulates fear memory expression. Cell. (2016) 166:716-28. doi: 10.1016/j.cell.2016.06.026

81. Michaelides M, Miller ML, Egervari G, Primeaux SD, Gomez JL, Ellis RJ, et al. Striatal Rgs4 regulates feeding and susceptibility to diet-induced obesity. Mol Psychiatry. (2018) doi: 10.1038/s41380-018-0120-7

82. Njemanze PC, Kranz M, Amend M, Hauser J, Wehrl H, Brust P. Gender differences in cerebral metabolism for color processing in mice: a PET/MRI Study. PLoS ONE. (2017) 12:e179919. doi: 10.1371/journal.pone.0179919

83. Rohleder C, Jung F, Mertgens H, Wiedermann D, Sue M, Neumaier B, et al. Neural correlates of sensorimotor gating: a metabolic positron emission tomography study in awake rats. Front Behav Neurosci. (2014) 8:178. doi: $10.3389 /$ fnbeh. 2014.00178

84. Sokoloff L, Reivich M, Kennedy C, Des Rosiers MH, Patlak CS, Pettigrew $\mathrm{KD}$, et al. The [14C]deoxyglucose method for the measurement of local cerebral glucose utilization: theory, procedure, and normal values in the conscious and anesthetized albino rat. J Neurochem. (1977) 28:897-916. doi: 10.1111/j.1471-4159.1977.tb10649.x

85. Leonard JP, Nowotnik DP, Neirinckx RD. Technetium-99m-d, 1-HM-PAO: a new radiopharmaceutical for imaging regional brain perfusion using SPECTa comparison with iodine-123 HIPDM. J Nucl Med. (1986) 27:1819-23.

86. Koretsky AP, Silva AC. Manganese-enhanced magnetic resonance imaging (MEMRI). NMR Biomed. (2004) 17:527-31. doi: 10.1002/nbm.940

87. Angelis GI, Ryder WJ, Gillam JE, Boisson F, Kyme AZ, Fulton RR, et al. Rigid motion correction of dual opposed planar projections in single photon imaging. Phys Med Biol. (2017) 62:3923-43. doi: 10.1088/1361-6560/aa68cd

88. Kyme AZ, Judenhofer MS, Gong K, Bec J, Selfridge A, Du J, et al. Open-field mouse brain PET: design optimisation and detector characterisation. Phys Med Biol. (2017) 62:6207-25. doi: 10.1088/1361-6560/aa7171

89. Baba JS, Endres CJ, Foss CA, Nimmagadda S, Jung H, Goddard JS, et al. Molecular imaging of conscious, unrestrained mice with AwakeSPECT. J Nucl Med. (2013) 54:969-76. doi: 10.2967/jnumed.112.109090

90. Schulz D, Southekal S, Junnarkar SS, Pratte JF, Purschke ML, Stoll SP, et al. Simultaneous assessment of rodent behavior and neurochemistry using a miniature positron emission tomograph. Nat Methods. (2011) 8:347-52. doi: 10.1038/nmeth.1582

91. Deffieux T, Demene C, Pernot M, Tanter M. Functional ultrasound neuroimaging: a review of the preclinical and clinical state of the art. Curr Opin Neurobiol. (2018) 50:128-35. doi: 10.1016/j.conb.2018.02.001

92. Sieu LA, Bergel A, Tiran E, Deffieux T, Pernot M, Gennisson JL, et al. EEG and functional ultrasound imaging in mobile rats. Nat Methods. (2015) 12:831-4. doi: 10.1038/nmeth.3506

93. Bergel A, Deffieux T, Demene C, Tanter M, Cohen I. Local hippocampal fast gamma rhythms precede brain-wide hyperemic patterns during spontaneous rodent REM sleep. Nat Commun. (2018) 9:5364. doi: 10.1038/s41467-018-07752-3

94. Mace E, Montaldo G, Trenholm S, Cowan C, Brignall A, Urban A, et al. Whole-Brain functional ultrasound imaging reveals brain modules for visuomotor integration. Neuron. (2018) 100:1241-51.e7. doi: 10.1016/j.neuron.2018.11.031

95. He Q, Wang J, Hu H. Illuminating the activated brain: emerging activitydependent tools to capture and control functional neural circuits. Neurosci Bull. (2019) 35:369-77. doi: 10.1007/s12264-018-0291-x

Conflict of Interest: The authors declare that the research was conducted in the absence of any commercial or financial relationships that could be construed as a potential conflict of interest.

Copyright () 2020 Oelschlegel and Goldschmidt. This is an open-access article distributed under the terms of the Creative Commons Attribution License (CC BY). The use, distribution or reproduction in other forums is permitted, provided the original author(s) and the copyright owner(s) are credited and that the original publication in this journal is cited, in accordance with accepted academic practice. No use, distribution or reproduction is permitted which does not comply with these terms. 